\title{
Data-driven decision making via sales analytics: introduction to the special issue
}

\author{
J. Ricky Fergurson ${ }^{1}$
}

Published online: 26 July 2020

(c) Springer Nature Limited 2020

Sales powers business throughout the world. While sales (and marketing) literature has spent much time exploring analytics and measurement, there seems to be a revitalized interest in sales and especially sales data and analytics. Marketing analytics powers the current wave of data-driven decision making, and leveraging strategic data remains a source of building a sustainable competitive advantage. In Volume 1, edition 1 of Journal of Marketing Analytics, Breur (2013, p. 1) proclaimed in the journal's first editorial,

We're drowning in data. Structured data, unstructured data, 'Big Data,' in an increasingly digital world, we create even more data. According to an IDC report, the global growth in data volumes amounts to about 60 percent per year. That means it will grow tenfold every 5 years!.

As we stand here seven years later, the available amount of data has grown exponentially due to the increased connectivity and data availability made possible by technology increasingly permeating the sales profession. Salespeople, sales managers, and executives must quickly make sense of oceans of sales-related data. With this influx of sales data, organizations need to develop actionable insights for their sales teams and their clients. The Sales Education Foundation (2020) notes that sales-specific research is necessary for bridging the gap between academia and industry. In reinforcing this need, the Sales Education Foundation has provided more than $\$ 125,000$ in grants to promote high-quality sales research since 2011. (Sales Education Foundation 2020).

Additionally, more universities are beginning to add sales analytics to their available sales courses. Given this increased availability of sales data and information and

J. Ricky Fergurson

ricky.fergurson@indstate.edu

1 Scott College of Business, Indiana State University, Terre Haute, Room 215, 30 N. 7th Street, Federal Hall, IN 47809, USA the apparent growing demand for sales research, I feel that reaching a better understanding of sales analytics is paramount in academic research. That is why I felt honored to be invited to edit this special issue on sales analytics.

The business world changes rapidly, and organizations must be able to help there sales teams adapt to these changes. Sales managers need the availability to quickly access published research to gain insights into best practices and solid methodology to deal with their daily challenges (Sales Education Foundation 2020). With the recent upheaval of industry due to the COVID-19 pandemic, the potential rise or fall of some corporations hinges on their ability to leverage sales data assets quickly and effectively. The goal of the Journal of Marketing Analytics has always been to incorporate rigorous research methods with real-world cases so that academics and industry professionals can stay on top of the latest trends and cutting-edge analytics. Measurement has always played a pivotal role in connecting theoretical concepts, and the conclusions reached about these concepts in academic research. As noted by Krishen and Petrescu (2018, p. 117), "Metrics and data are empty shells without proper theories and interpretations behind them." Hall and Lee (2019) reinforced this insight in the Journal of Personal Selling $\&$ Sales Management's special edition on "Measurement in Sales Research" by accentuating the strong links between theories, empirical data, and research conclusions.

As I set out to consider the many submissions for this special issue and extend invitations to reviewers, it was inspiring to see the high commitment level by sales scholars. The overarching goal was to meld strong theoretical and empirical analytics research in sales and sales management. The articles published in this special issue accomplish that goal and offer insightful views into each of their chosen topics. In each article, the authors' insights and perspectives lay a foundation that should be considered for future academic research. The first two articles provide a common theme in regard to using CRM. 
First, Hoyle et al. dissect how sales managers and salespeople are using the modern-day tools at their disposal to achieve accurate sales forecasting and the resulting impacts. In doing so, this article examines factors that influence the type of forecasting used and potential explanations for why. While recognizing the importance of data-driven decisions and predictive analytics in organizational success and the ability to improve day-to-day efficiencies, Hoyle et al.'s research demonstrates that there is a lack of action and follow through on these ideals among both sales managers and salespeople. This research offers several managerial contributions relating to the process of sales forecasting. It also puts forth a call for further research on forecasting, including the role of varied CRM and ERP systems, sales force automation, and other technologies to identify the diverse impacts on forecasting, planning, and goal setting.

Second, Rodriguez and Boyer integrate Technology Acceptance Model (TAM) and IS success model to explore the influence (Mobile CRM) mCRM has on sales performance. This article applies an adaptation of mCRM to salespeople in a business-to-business context. This research also helps elucidate the role mCRM plays in traditional CRM adoption.

In the other two articles, Merkle et al. use a unified theory of brand equity to explore the decline of Major League Baseball (MLB) ticket sales and game attendance within the framework of MLB brand equity. Additionally, this research examines the mediating role of attendance and local television and the moderating role of Twitter followers in the relationships between MLB marketing assets and the financial performance of the teams using secondary data from multiple sources. Additionally, Said looks at a bibliometric analysis of salesforce research from 1912-2019 to put forth a four-step procedure to merge SCOPUS and Web of Science databases when performing a bibliometric analysis. This research demonstrates that doing separate bibliometric analyses of each database does not prove a complete picture of the state of knowledge and tendencies in a field.
It was my pleasure to work with the reviewers and authors to put this special issue together. As I feel that critical research into sales analytics is still in its infancy, I hope that this special issue lays a foundation for the academic community to conduct further sales analytics research.

\section{References}

Breur, T. 2013. Editorial. Journal of Marketing Analytics 1: 1-2.

Hall, Z.R., and N. Lee. 2019. Taking the measure of measurement in sales research: Introduction to the special issue. Journal of Personal Selling \& Sales Management 39 (3): 201-206.

Krishen, A.S., and M. Petrescu. 2018. Marketing analytics: Delineating the field while welcoming crossover. Journal of Marketing Analytics 6: 117-119.

Sales Education Foundation. 2020. Elevating sales research. https:// salesfoundation.org/elevating-sales/sales-research/. Accessed 14 June 2020.

Publisher's Note Springer Nature remains neutral with regard to jurisdictional claims in published maps and institutional affiliations.

Ricky Fergurson is Assistant Professor of Marketing, Indiana State University. He earned his Ph.D. from the University of North Texas. He currently teaches Professional Selling in the Scott College of Business at Indiana State University. Before joining the faculty at Indiana State University, he taught for 2 years at Nova Southeastern University in Ft. Lauderdale, FL. His teaching philosophy is a belief that all learning experiences should be engaging and enlightening. He draws on his experience in sales and marketing to incorporate real-world issues into his classroom teachings. His research and teaching interests include B2B Sales, Sales Management, and Relationship Marketing. He has research published in the Journal of Managerial Issues and Journal of Marketing Channels. He has presented papers at several academic conferences including the Academy of marketing Science, the Society for Marketing Advances, National Conference in Sales Management, and the TX Ph.D. Research Conference. He has also served as a reviewer for academic journals and conferences. 